\title{
Excessive Daytime Sleepiness and Its Risk Factors for Commercial Bus Drivers in Korea
}

\author{
Sung Min Kim, MD ${ }^{1,2}$, Yoo Hyun Um, MD, PhD ${ }^{1,2}$, Tae-Won Kim, MD ${ }^{1,2}$, Jong-Hyun Jeong, MD, PhD ${ }^{1,2}$, \\ Ho-Jun Seo, MD, $\mathrm{PhD}^{1,2}$, Ji Hyun Song, BSc${ }^{3}$, Seung-Chul Hong, MD, PhD ${ }^{1,2}$ \\ 'Department of Psychiatry, College of Medicine, The Catholic University of Korea, Seoul, Korea \\ 2Sleep Disorders Clinic, Department of Psychiatry, St. Vincent's Hospital, College of Medicine, The Catholic University of Korea, Suwon, Korea \\ ${ }^{3}$ Asia Sleep Epidemiology Center, Department of Psychiatry, St. Vincent's Hospital, College of Medicine, The Catholic University of Korea, Suwon, Korea
}

Received: December 21, 2017

Revised: December 27, 2017

Accepted: December 27, 2017

Correspondence

Seung-Chul Hong, MD, PhD

Sleep Disorders Clinic,

Department of Psychiatry,

St. Vincent's Hospital,

College of Medicine,

The Catholic University of Korea,

93 Jungbu-daero, Paldal-gu,

Suwon 16247, Korea

Tel +82-31-249-8216

Fax +82-31-248-6758

E-mail hscjohn@hotmail.com

ORCID

Sung Min Kim

https://orcid.org/0000-0002-3082-4014

Yoo Hyun Um

https://orcid.org/0000-0002-3403-4140

Tae-Won Kim

https://orcid.org/0000-0003-2689-202X

Jong-Hyun Jeong

https://orcid.org/0000-0003-3570-7607

Ho-Jun Seo

https://orcid.org/0000-0003-1661-1394

Ji Hyun Song

https://orcid.org/0000-0002-0128-2869

Seung-Chul Hong

https://orcid.org/0000-0003-0828-2906
Background and Objective Recent research has found the high prevalence of excessive daytime sleepiness (EDS) among commercial bus drivers which may induce serious physical injury and economic damages. However, there are limited data revealing the risk factors of EDS among these workers. Therefore, we investigated the EDS in commercial bus drivers and its risk factors.

Methods Self-report questionnaires were given to 842 city bus drivers in Suwon, Korea, that included demographic characteristics, the Epworth Sleepiness Scale, Pittsburgh Sleep Quality Index, Insomnia Severity Index, and Berlin Questionnaire. The logistic regression analysis was conducted to investigate the risk factors of EDS among commercial bus drivers.

Results The average of body mass index and total sleep time of 304 responding drivers were 24.7 $\pm 3.2 \mathrm{~kg} / \mathrm{m}^{2}, 6.05 \pm 1.51$ hours, respectively. Among them, 13.2\% reported an Epworth sleepiness score $>10$. The majority of the responders reported suffering from poor sleep quality (68.4\%) and $10.2 \%$ reported having a moderate to severe insomnia. The proportion of group with high risk for obstructive sleep apnea (OSA) was $26.7 \%$. In multivariate regression analysis, only three variables, including poor quality of sleep, insomnia, and high risk for OSA, were significantly associated with EDS.

Conclusions This study has shown a high prevalence of EDS and insomnia, poor quality of sleep and high risk for OSA as risk factors of EDS among commercial bus drivers in Korea.

Sleep Med Res 2017;8(2):76-80

Key Words Excessive daytime sleepiness, Sleep quality, Insomnia, Obstructive sleep apnea, Bus driver.

\section{INTRODUCTION}

Drowsy driving has become a social issue that has induced serious physical injury and economic damages over two decades. Previous studies have shown that $1-6 \%$ of all road crash involved fatigue or sleepiness of drivers and the proportion increased to $3-15 \%$ in all cases of fatal crashes. ${ }^{1}$ Considering that $37-41 \%$ of drivers reported that they had at least one or more experience of falling asleep when driving since beginning to their driving career, ${ }^{2-4}$ sleepiness during driving is thought to be a wide-spread problem in modern society.

Although traffic accidents by large trucks and buses tended to be fatal compared to traffic accidents by cars, ${ }^{5}$ the sleepiness of professional drivers while at work has not been managed appropriately. Recent studies revealed that the proportion of truck drivers experiencing crashes involving sleepiness or fatigue reached $2-41 \%$, and the rate of those with fatal crashes was 4-31\%, not lower than that of non-professional drivers. ${ }^{1}$

In order to examine and manage this public-health issue, there have been studies aimed at 
the risk factors of drowsy driving among commercial drivers. Obstructive sleep apnea (OSA) is the well-accepted risk factor of excessive daytime sleepiness (EDS) of commercial vehicle drivers. ${ }^{6}$ Drivers with OSA are known to have increased risk of accidents, two- to 15 -fold higher than the general population, ${ }^{7,8}$ Additionally, variables including exercise, insufficient sleep, snoring, sleep quality, general health condition, and stress were significantly associated with EDS among city bus drivers. ${ }^{9}$

However, studies conducted by the public institutions were focused on delineating the risk factors of traffic accidents by commercial vehicles, not on EDS. These approaches highlighted some limitations for interpreting the findings related to EDS due to a possibility of confounding bias. In addition, previous studies applied relatively uncommon questionnaires for investigating the risk factors of EDS among commercial drivers, which prohibits the comparison with variable researches and application to actual situations. Furthermore, to our knowledge, domestic data on the risk factors of sleepiness for commercial bus drivers have not yet been published.

Therefore, we set a goal to investigate the prevalence of EDS and other variables among commercial bus drivers with commonly used and easily accepted questionnaires. Next, the relationships between EDS and other variables were explored for revealing risk factors of EDS among bus drivers. We hypothesized that commercial bus drivers experience daytime sleepiness during driving, which is caused by demographic factors, reduced sleep quality, insomnia, and OSA.

\section{METHODS}

\section{Participants}

All city bus drivers in Suwon, Republic of Korea were recruited to participate in the study between October, 26, 2017 and November, 31, 2017. We contacted the union representatives of bus companies located in Suwon to gain permission to approach the drivers. A list of companies that employed all city bus drivers was obtained from the representatives of the union, and researchers visited these companies to provide questionnaires to those who agreed to participate. Questionnaires were distributed and collected by union officials under the supervision of researchers. The questionnaires also included contact information of investigators in order to easily accommodate participants' queries. Among candidates, we excluded subjects who did not fully complete the questionnaires or did not belong to a group between the ages of 18-70.

\section{Study Design and Data Collection}

A cross-sectional study was performed with self-report questionnaires distributed to commercial bus drivers. Complete confidentiality was obtained from unnamed questionnaires through data collection and processing. All questionnaires were reviewed by union officials of the bus companies before being distributed to workers in order to ascertain convenience of answering and possible disadvantages to bus drivers. Participants requested additional assurances that participating in the survey would not have any adverse effects to their jobs. Included in the questionnaires were demographic characteristics, the Epworth Sleepiness Scale (ESS), Pittsburgh Sleep Quality Index (PSQI), the Insomnia Severity Index (ISI), Berlin questionnaire (BQ).

In the section on demographic characteristics, a newly created form of self-report questionnaire was administered. The items were comprised of gender, age, height, weight, marital status, habitant status, professional driving career length, comorbid medical condition, and medication history of the use of sleeping pills. For detecting sleepiness during driving, the ESS was applied, which provides a measure for EDS in daily life through the use of eight questions. ${ }^{10}$ Total scores of ESS range from $0-24$, and the cut-off value for EDS is $10 .^{11,12}$ The ESS shows its reliability and validity for screening daytime sleepiness in Korea. ${ }^{13}$

The PSQI was used for evaluating the sleep quality of participants. This self-reported scale is composed of questions that measure the quantitative and subjective aspects of sleep, ${ }^{14}$ and the Korean version of PSQI was developed in $2011 .{ }^{15}$ The ISI was presented to bus drivers to measure their perception of insomnia severity. ${ }^{16}$ The total score of ISI are divided into four subcategories, including $0-7$, no clinically significant insomnia; 8-14, subthreshold insomnia; 15-21, moderate insomnia; and 22-28, severe insomnia. We used a cut-off score of 15 , accepted as the threshold for clinically significant insomnia in the Korean version of ISI. ${ }^{17}$

For screening OSA among commercial drivers, BQ, which is a self-reported scale commonly used for detecting individuals with high risk for OSA ${ }^{18,19}$ was applied. BQ is consists of three sections: snoring, daytime sleepiness or fatigue, and medical and anthropometric condition. In the event of having two or more sections with positive scores, subjects are classified as high risk for OSA. The ethical approval of the study was received by the Institutional Review Board (IRB) of St. Vincent's Hospital, Suwon, Republic of Korea. And the IRB granted a waiver of documentation of consent in the study (Study No. VC17QCSI0196).

\section{Statistical Analysis}

Collected data were analyzed using SPSS 20.0 software (IBM Corp., Armonk, NY, USA). The descriptive statistics were shown as mean \pm standard deviations and percentages, depending on each characteristic. Participants' answers were assessed by the deadline of each questionnaire and all statistics were converted into binary variables. Then, the univariate association between EDS and binary variables were analyzed using the logistic regression model. Among the variables, those shown to have a significant association with EDS were analyzed with multiple regression analysis to investigate the independent role of each variable. Odds ratio (OR) and 95\% confidence interval (CI) were indi- 
cated in the tables. All significance levels were set to 0.05 .

\section{RESULTS}

Results show that 304 subjects of 842 drivers completed questionnaires, registering a completion rate of $36 \%$. The mean age of responding drivers was $51.08 \pm 6.93$, and only 10 (3.3\%) were women. Of participants, $74.0 \%$ were categorized as married and $4.3 \%$ used sleeping medication. Those who reported having at least one comorbid medical condition were $29.3 \%$, and almost half were considered obese (body mass index $>25$; $44.7 \%$ ). All participants worked every two days, having one day

Table 1. Demographic and clinical characteristics of the participants

\begin{tabular}{lc}
\hline \multicolumn{1}{c}{ Characteristics } & $\begin{array}{c}\text { Mean } \pm \text { SD or } \\
\text { percent }\end{array}$ \\
\hline Age (year) & $51.1 \pm 6.9$ \\
Female (\%) & $3.3(\mathrm{n}=10)$ \\
BMI $\left(\mathrm{kg} / \mathrm{m}^{2}\right)$ & $24.7 \pm 3.2$ \\
Overweight $\left(25 \mathrm{~kg} / \mathrm{m}^{2}>\mathrm{BMI} \geq 23 \mathrm{~kg} / \mathrm{m}^{2}\right)(\%)$ & 25.3 \\
Obesity $\left(\mathrm{BMI} \geq 25 \mathrm{~kg} / \mathrm{m}^{2}\right)(\%)$ & 44.7 \\
Sleeping pill $(\%)$ & 4.3 \\
Comorbid medication condition $(\%)$ & 29.3 \\
Hypertension (\%) & 22.7 \\
Diabetes (\%) & 8.6 \\
Coronary heart disease $(\%)$ & 2.0 \\
Cerebrovascular disease $(\%)$ & 0.3 \\
Thyroid disease (\%) & 0.7 \\
Years of driving professionally (year) & $16.85 \pm 11.19$ \\
Daily working hours (hour) & $16.45 \pm 2.59$ \\
Married (\%) & 74.0 \\
\hline SD: &
\end{tabular}

SD: standard deviation, BMI: body mass index. off between working days. On work days, commercial bus drivers worked for a relatively long $(16.45 \pm 2.59)$ hours , as they were assigned to a single bus route throughout the day (Table 1).

In the study, the drivers usually went to sleep at 22:07 \pm 1:34 and wake up at 05:22 $\pm 1: 45$. And they reported that $20.6 \pm$ 13.7 minutes were needed to fall asleep in bed, subjectively. Total sleep time of bus drivers was $6.05 \pm 1.51$ hours and sleep efficiency was $88.1 \%$. Of the responding bus drivers, 40 subjects (13.2\%) reported they scored more than 10 in ESS and 208 drivers (68.4\%) reported a PSQI score of more than five, indicating poor quality of sleep. Thirty-one drivers (10.2\%) rated more than 15 in ISI and $27.6 \%$ of the sample was evaluated as the high-risk group of OSA (Table 2).

On univariate logistic regression analysis, background variables, such as gender, comorbid medical condition, obesity, sleeping pill medication, and marital status were not statistically

Table 2. Sleep parameters of the participants

\begin{tabular}{lc}
\hline \multicolumn{1}{c}{ Sleep parameters } & Mean \pm SD or percent \\
\hline Total sleep time (hour) & $6.05 \pm 1.51$ \\
Sleep efficiency (\%) & 88.1 \\
ESS score & $6.55 \pm 4.24$ \\
ESS > 10 (\%) & 13.2 \\
PSQI score & $7.91 \pm 4.38$ \\
PSQI > 5 (\%) & 68.4 \\
ISI score & $7.01 \pm 5.70$ \\
Not insomnia (\%) & 59.9 \\
Subthreshold insomnia (\%) & 29.9 \\
Moderate insomnia (\%) & 8.2 \\
Severe insomnia (\%) & 2.0 \\
High risk for OSA in BQ (\%) & 27.6 \\
\hline
\end{tabular}

SD: standard deviation, ESS: Epworth Sleepiness Scale, PSQI: Pittsburgh Sleep Quality Index, ISI: Insomnia Severity Index, OSA: obstructive sleep apena, BQ: Berlin Questionnaire.

Table 3. Associations of excessive daytime sleepiness with the risk factors of commercial bus drivers

\begin{tabular}{|c|c|c|c|c|}
\hline \multirow{2}{*}{ Variables } & \multicolumn{2}{|c|}{ Logistic regression } & \multicolumn{2}{|c|}{ Multiple regression } \\
\hline & $\mathrm{p}$ & OR $(95 \% \mathrm{CI})$ & $\mathrm{p}$ & OR $(95 \% \mathrm{CI})$ \\
\hline Female & 0.126 & $2.98(0.74-12.02)$ & & \\
\hline Comorbid medical condition & 0.222 & $1.54(0.77-3.09)$ & & \\
\hline Obesity & 0.706 & $1.14(0.58-2.21)$ & & \\
\hline Sleeping pill & 0.808 & $1.21(0.26-5.67)$ & & \\
\hline Married & 0.879 & $1.06(0.49-2.29)$ & & \\
\hline PSQI $>5$ & $0.004^{*}$ & $4.81(1.66-13.94)$ & $0.025^{*}$ & $3.50(1.17-10.52)$ \\
\hline ISI $>15$ & $0.002^{*}$ & $3.86(1.86-8.96)$ & $0.034^{*}$ & $2.65(1.08-6.50)$ \\
\hline High risk for OSA in $B Q$ & $<0.001^{*}$ & $4.37(2.15-8.90)$ & $<0.001^{*}$ & $3.93(1.90-8.14)$ \\
\hline
\end{tabular}

*p-value $<0.05$.

OR: odds ratio, CI: confidence interval, PSQI: Pittsburgh Sleep Quality Index, ISI: Insomnia Severity Index, OSA: obstructive sleep apnea, BQ: Berlin Questionnaire. 
associated with EDS of commercial bus drivers (Table 3). Conversely, poor quality of sleep (PSQI > 5), insomnia (ISI > 15), and high risk of OSA emerged as significant risk factors for EDS. The three risk factors remained significant in multiple regression analysis.

\section{DISCUSSION}

The study aimed to investigate the current state of EDS and its risk factors among commercial bus drivers in Korea. The results showed that $13.2 \%$ of responding drivers were suffering from EDS during work hours and $68.4 \%$ experienced poor quality of sleep. Among participants, 10.2\% were suspicious for having insomnia and $27.6 \%$ were assessed as high risk for OSA. Logistic regression model analysis indicated that only three variables were significantly associated with EDS of bus drivers; PSQI $>5(\mathrm{p}=0.004, \mathrm{OR}=4.81, \mathrm{CI}=1.66-13.94), \mathrm{ISI}>15$ ( $\mathrm{p}=$ $0.002, \mathrm{OR}=3.86, \mathrm{CI}=1.86-8.96)$, and high risk for OSA $(\mathrm{p}<$ $0.001, \mathrm{OR}=3.86, \mathrm{CI}=1.86-8.96$ ).

It was shown that bus drivers in Korea tended to sleep during an average time of $6.05 \pm 1.51$ hours a day, which was relatively shorter than the average of general population in Korea, 7.68 hours a day. ${ }^{20}$ This finding indicated that bus drivers work under sleep deprivation of more than two hours ${ }^{21}$ which was known to raises the risk of motor vehicle accidents among commercial drivers. ${ }^{22}$ The working patterns of bus drivers in the study could prohibit enough sleep because they had to get up early around 05:00 in the morning. Providing a free time for napping and resting would be one of the solutions which could avoid daytime sleepiness and road crashes of commercial drivers. ${ }^{22}$

Compared with the surveys that revealed the rate of EDS among professional drivers ranging from $4.7-20 \%,{ }^{23-25}$ the prevalence of EDS was consistent with previous data. However, considering that our findings were based on self-report scales, the prevalence in this study was possible to underestimate. Since $27.6 \%$ of participants were categorized as high risk for OSA which is the main risk factor of EDS, the possibility of underestimating EDS obtained its ground.

The rate of insomnia, which is a common problem among professional drivers, has been reported a range of $18.9 \%$ and $37.5 \%$ over two decades. ${ }^{26,27}$ In the present study, $10.2 \%$ of bus drivers reported having insomnia, but the rate was lower than other studies, which could be the reason we excluded the group of subthreshold insomnia when assessing insomnia. Only a small group of drivers with insomnia ( $4.3 \%$ of sample) were being treated with sleep medication, indicating that appropriate approaches to treat insomnia symptoms should be arranged.

Further, we found that almost one of four participating bus drivers were at high risk for OSA, as the previous results ranged between $17 \%$ and $28 \%{ }^{24,28,29}$ Long working hours and poor dietary habits were thought to be the cause of high prevalence for
OSA. ${ }^{30,31}$ Considering that OSA among bus drivers has a significant relationship with crash history, ${ }^{32}$ OSA is assumed as a considerable safety issue for commercial drivers.

Unlike previous studies investigating the risk factors of EDS, ${ }^{33,34}$ demographic characteristics, such as age (not shown in the article), gender, and obesity were not significantly associated with EDS. Otherwise, variables including insomnia, poor quality of sleep, and high risk for OSA were the significant risk factors of EDS among commercial drivers in the logistic regression analysis. This indicates that a medical approach for evaluating the sleep patterns of bus drivers is crucial for developing a model to manage EDS among them.

Nevertheless, there are some limitations of this study. Due to its cross-sectional design, we could not establish any conclusive inference, only the presumptive relationships of EDS and variables. Moreover, our sample included only three female drivers, so the prevalence of problems observed in the study cannot be accepted as a true estimate of all professional drivers. However, the ratio of female drivers was $2.1 \%$ in Seoul, Korea, ${ }^{35}$ so these findings can be helpful for implicating domestic conditions. Also, the impact of alcohol, smoking and caffeine on EDS was not discussed in the study, which can influence the relationship between other variables and EDS. The items asking these factors were withdrawn from questionnaires in consideration of reliability for answering.

Finally, the clinical characteristics surrounding the sleep of bus drivers were investigated by self-report questionnaires, not by objective methods, such as polysomnography or actigraphy. Owing to this limitation, readers should be careful to accept the results of the study. The results could be biased by self-selection, which might influence the observed associations. Additionally, the recall bias could have been produced by the use of retrospective scale asking the event during the past 1-3 months, which may decrease the reliability of the study. Furthermore, Sadeghniiat-Haghighi et al. ${ }^{36}$ have claimed the study that ESS is not an effective tool for detecting EDS, compared with the maintenance of wakefulness test that is assumed as the most reliable tool of detecting daytime sleepiness.

In conclusion, a high prevalence of EDS among commercial bus drivers in Korea was seen. Those suffering from insomnia or poor sleep quality, and assessed as high risk for OSA have an increased risk of daytime sleepiness. Therefore, screening for those risk factors should be a primary concern for establishing safety in professional driving.

\section{Conflicts of Interest}

The authors have no financial conflicts of interest.

\section{Authors' Contribution}

Conceptualization: Um YH, Kim TW, Jeong JH, Seo HJ, Hong SC. Data curation: Kim SM, Kim TW, Song JH. Formal analysis: Kim SM. Investigation: Kim SM, Song JH, Hong SC. Methodology: Kim SM, Um YH, Kim TW, Song JH. Project administration: Hong SC. Resources: Kim SM, Song JH, Hong SC. Supervision: Jeong JH, Seo HJ. Validation: Kim 
SM, Jeong JH, Seo HJ. Writing-original draft: Kim SM. Writing-review \& editing: Um YH, Song JH, Hong SC.

\section{REFERENCES}

1. Sagberg F; Transportoekonomisk Institutt (Norway); Commission of the European Communities. Fatigue, sleepiness and reduced alertness as risk factors in driving. Oslo: The Institute 2004.

2. Higgins JS, Michael J, Austin R, Åkerstedt T, Van Dongen HP, Watson $\mathrm{N}$, et al. Asleep at the wheel-the road to addressing drowsy driving. Sleep 2017;40:zsx001.

3. Royal D. National survey of distracted and drowsy driving attitudes and behavior: 2002. Washington DC: National Highway Traffic Safety Administration; 2002 Apr. 68 p. Report No.: DOT HS 809566.

4. Tefft BC. The prevalence and impact of drowsy driving. Washington DC: AAA Foundation for Traffic Safety; 2010.

5. Federal Motor Carrier Safety Administration. Commercial motor vechicle facts. Washington DC: U.S. Department of Transportation; 2013.

6. Gottlieb DJ, Whitney CW, Bonekat WH, Iber C, James GD, Lebowitz $\mathrm{M}$, et al. Relation of sleepiness to respiratory disturbance index: the sleep heart health study. Am J Respir Crit Care Med 1999;159:502-7.

7. Young T, Blustein J, Finn L, Palta M. Sleep-disordered breathing and motor vehicle accidents in a population-based sample of employed adults. Sleep 1997;20:608-13.

8. Terán-Santos J, Jiménez-Gómez A, Cordero-Guevara J. The association between sleep apnea and the risk of traffic accidents. Cooperative Group Burgos-Santander. N Engl J Med 1999;340:847-51.

9. Anund A, Ihlström J, Fors C, Kecklund G, Filtness A. Factors associated with self-reported driver sleepiness and incidents in city bus drivers. Ind Health 2016;54:337-46.

10. Johns MW. A new method for measuring daytime sleepiness: the Epworth sleepiness scale. Sleep 1991;14:540-5.

11. Kendzerska TB, Smith PM, Brignardello-Petersen R, Leung RS, Tomlinson GA. Evaluation of the measurement properties of the Epworth sleepiness scale: a systematic review. Sleep Med Rev 2014;18:321-31.

12. Johns MW. Reliability and factor analysis of the Epworth sleepiness scale. Sleep 1992;15:376-81.

13. Cho YW, Lee JH, Son HK, Lee SH, Shin C, Johns MW. The reliability and validity of the Korean version of the Epworth sleepiness scale. Sleep Breath 2011;15:377-84.

14. Buysse DJ, Reynolds CF 3rd, Monk TH, Berman SR, Kupfer DJ. The Pittsburgh Sleep Quality Index: a new instrument for psychiatric practice and research. Psychiatry Res 1989;28:193-213.

15. Sohn SI, Kim DH, Lee MY, Cho YW. The reliability and validity of the Korean version of the Pittsburgh Sleep Quality Index. Sleep Breath 2012; 16:803-12.

16. Bastien $\mathrm{CH}$, Vallières A, Morin CM. Validation of the Insomnia Severity Index as an outcome measure for insomnia research. Sleep Med 2001;2:297-307.

17. Cho YW, Song ML, Morin CM. Validation of a Korean version of the insomnia severity index. J Clin Neurol 2014;10:210-5.

18. Ahmadi N, Chung SA, Gibbs A, Shapiro CM. The Berlin questionnaire for sleep apnea in a sleep clinic population: relationship to polysomnographic measurement of respiratory disturbance. Sleep Breath 2008;12:39-45.
19. Kang K, Park KS, Kim JE, Kim SW, Kim YT, Kim JS, et al. Usefulness of the Berlin Questionnaire to identify patients at high risk for obstructive sleep apnea: a population-based door-to-door study. Sleep Breath 2013; 17:803-10.

20. OECD. Society at a glance 2016: OECD social indicators. Paris: OECD Publishing 2016.

21. Hirshkowitz M, Whiton K, Albert SM, Alessi C, Bruni O, DonCarlos L, et al. National Sleep Foundation's sleep time duration recommendations: methodology and results summary. Sleep Health 2015;1:40-3.

22. Garbarino S, Durando P, Guglielmi O, Dini G, Bersi F, Fornarino S, et al. Sleep apnea, sleep debt and daytime sleepiness are independently associated with road accidents. A cross-sectional study on truck drivers. PLoS One 2016 Nov 30 [Epub ahead of print]. https://doi.org/10.1371/ journal.pone. 0166262 .

23. Braver ER, Preusser CW, Preusser DF, Baum HM, Beilock R, Ulmer R. Long hours and fatigue: a survey of tractor-trailer drivers. J Public Health Policy 1992;13:341-66.

24. Asaoka S, Namba K, Tsuiki S, Komada Y, Inoue Y. Excessive daytime sleepiness among Japanese public transportation drivers engaged in shiftwork. J Occup Environ Med 2010;52:813-8.

25. Vennelle M, Engleman HM, Douglas NJ. Sleepiness and sleep-related accidents in commercial bus drivers. Sleep Breath 2010;14:39-42.

26. Partinen M, Eskelinen L, Tuomi K. Complaints of insomnia in different occupations. Scand J Work Environ Health 1984;10(6 Spec No):467-9.

27. Mello MT, Santana MG, Souza LM, Oliveira PC, Ventura ML, Stampi C, et al. Sleep patterns and sleep-related complaints of Brazilian interstate bus drivers. Braz J Med Biol Res 2000;33:71-7.

28. Kales SN, Straubel MG. Obstructive sleep apnea in North American commercial drivers. Ind Health 2014;52:13-24.

29. Hui DS, Chan JK, Ko FW, Choy DK, Li TS, Chan AT, et al. Prevalence of snoring and sleep-disordered breathing in a group of commercial bus drivers in Hong Kong. Intern Med J 2002;32:149-57.

30. Sieber WK, Robinson CF, Birdsey J, Chen GX, Hitchcock EM, Lincoln JE, et al. Obesity and other risk factors: the national survey of U.S. long-haul truck driver health and injury. Am J Ind Med 2014;57:615-26.

31. Jack FR, Piacentini MG, Schröder MJ. Perception and role of fruit in the workday diets of Scottish lorry drivers. Appetite 1998;30:139-49.

32. Razmpa E, Sadegh Niat K, Saedi B. Urban bus drivers' sleep problems and crash accidents. Indian J Otolaryngol Head Neck Surg 2011;63:26973.

33. Whitney CW, Enright PL, Newman AB, Bonekat W, Foley D, Quan SF. Correlates of daytime sleepiness in 4578 elderly persons: the cardiovascular health study. Sleep 1998;21:27-36.

34. Lee HJ, Oh KS, Kim T, Lee CS, Jeong J, Youn SY, et al. Prevalence, risk factors, and impact of excessive daytime sleepiness in an elderly Korean population. Sleep Med Res 2014;5:54-61.

35. Current status of public transportation of Seoul. Seoul Metropolitan Government [updated 2017 July 5]. Available from: http://traffic.seoul. go.kr/archives/300.

36. Sadeghniiat-Haghighi K, Moller HJ, Saraei M, Aminian O, KhajehMehrizi A. The Epworth sleepiness scale for screening of the drowsy driving: comparison with the maintenance of wakefulness test in an Iranian sample of commercial drivers. Acta Med Iran 2014;52:125-9. 